\title{
A Study on Accuracy according to Operators' Skilled Level and Implant Sites with/without Computer-Guide Template
}

\author{
Richard Leesungbok * / Co-author; Su-Jung Park \\ *DMD, MSD, PhD. Head Prof. \& Chair, Dept of Biomaterials \& Prosthodontics, \\ Kyung Hee University Dental School Hospital at Gangdong, Seoul, Korea Republic of
}

\begin{abstract}
The availability of advanced computer-aided design/computer-assisted manufacturing (CAD/CAM) technology permits optimal planning for implant placement, using image data to guide the surgical intervention via rapid prototyping technology. This approach allows for precise measurement of the location of relevant anatomical structures and reduces the risk of damaging them during the surgical procedures. In addition, this approach can be expected to minimize operator-dependent results. This study examined whether use of a Computer-Guide Template reduces deviations related to differences in the surgeons' experience levels and in anterior-posterior implant placement sites.

Key words; CAD/CAM, Computer-Guide Template, deviation parameters, degree, coronal, apex, depth
\end{abstract}

\section{Background and Aim}

This in vitro study evaluated the reliability of a surgical guide with regard to different levels of operator surgical experience and implant site with/without Computer-Guide Template.

\section{Methods and Materials}

A stereolithographic surgical guide for epoxy resin mandibles with three edentulous molar sites were produced using a computer-aided design/computer-assisted manufacture (CAD/CAM) system. Two surgeons with and two surgeons without implant surgery experience placed implants in a model either using or not using the Computer-Guide Template. Four groups were created: inexperienced surgeon without the guide (group 1); experienced surgeon without the guide (group 2); inexperienced surgeon with the guide (group 3); and experienced surgeon with the guide (group 4). Planned implants and placed implants were superimposed using digital software, and deviation parameters(degree, coronal, apex, and depth) were calculated. Wilcoxon two-sample test and Kruskal-Wallis test were used to analyze the results.

Table 1 The Four Groups in the Study

\begin{tabular}{lcc} 
Table 1 & The Four Groups in the Study \\
\hline & $\begin{array}{c}\text { Surgeon 1 } \\
\text { (inexperienced) }\end{array}$ & $\begin{array}{c}\text { Surgeon 2 } \\
\text { (experienced) }\end{array}$ \\
\hline Without surgical guide (manual) & Group 1 & Group 2 \\
\hline With CAD/CAM surgical guide & Group 3 & Group 4 \\
\hline
\end{tabular}

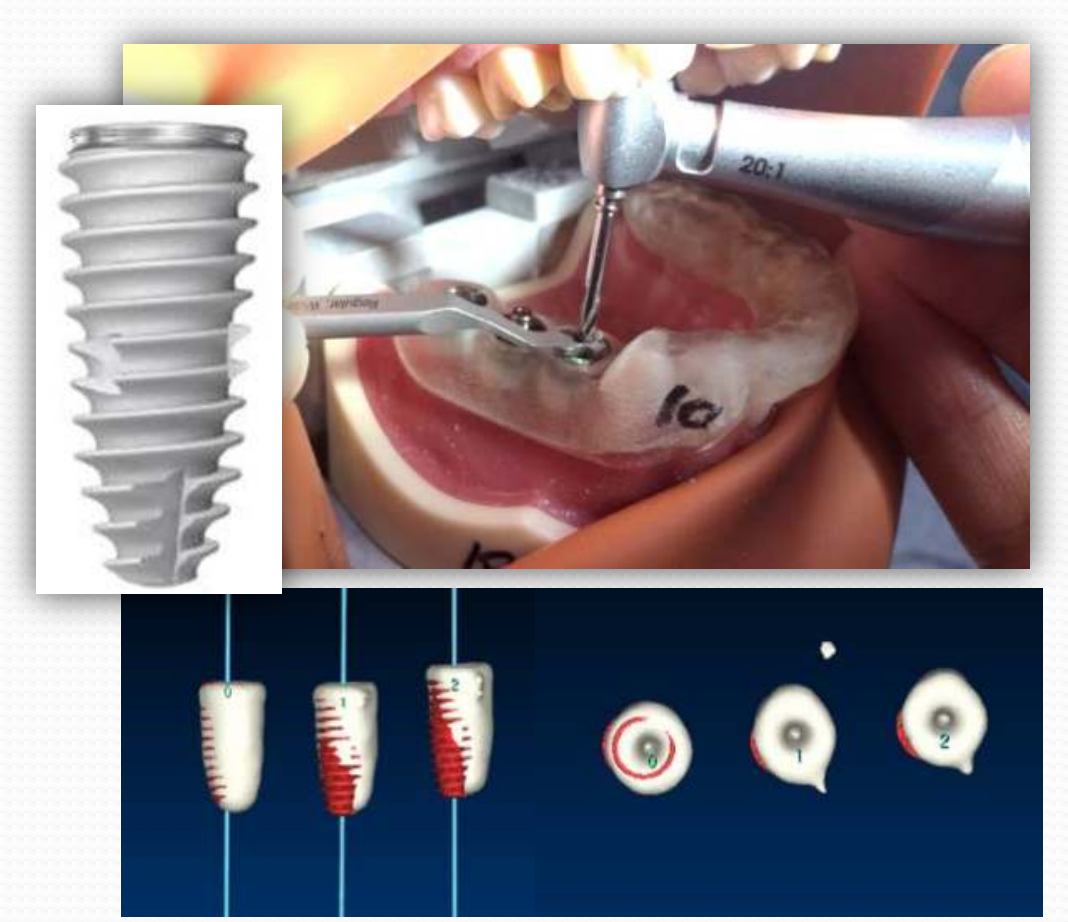

Fig 1 (a) The implants were inserted in the model with continuous drilling using the CAD/CAM surgical guide. (b) Superimposition of the planned (red) and placed (gray) implants using the CAD software.

Fig 2 Depiction of four
parameters of deviation,
calculated on angular,
coronal, apical, and
depth positions: (a) degree,
(b) coronal, (c)
apex, (d) depth.

\section{Results}

When groups 1 and 2 were compared, the differences in coronal and depth measurements were significant. However, when groups 3 and 4 were compared, none of the parameters differed significantly and deviations were reduced between and within the surgeon groups. There were no significant differences among the parameters for the different implant sites for all four groups. Anterior-posterior implant placement in the molar area was not affected by use or non-use of the Computer-Guide Template.

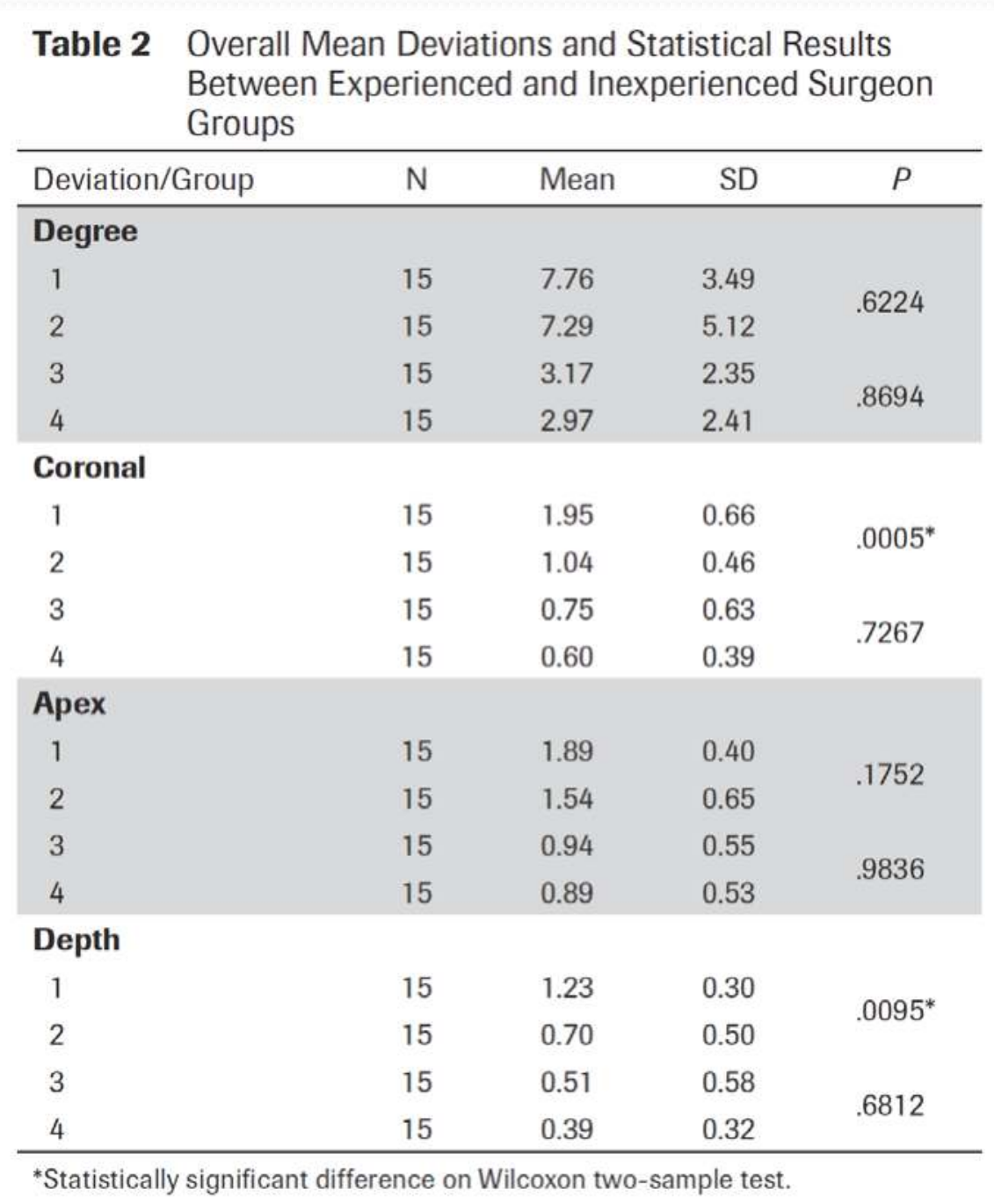
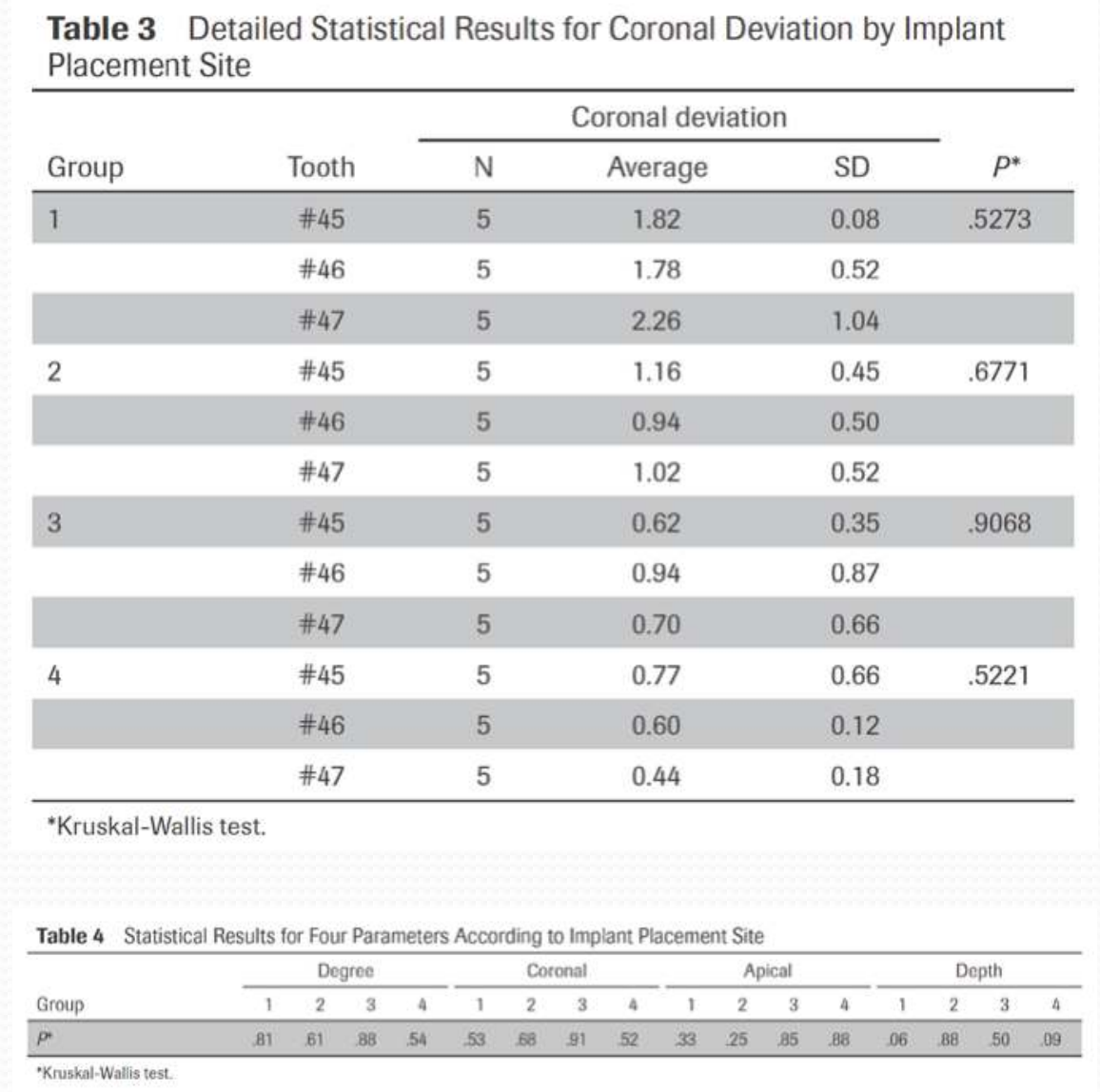

\section{Conclusions}

Within the limitations of this study, it can be concluded that the Computer-Guide Template can be used to reduce discrepancies in selected parameters both between and within groups. This should facilitate better results by dentists who have insufficient experience performing implant surgery. Differences in the anterior-posterior insertion site in the molar area did not affect the accuracy of implant placement with and without the Computer-Guide Template. Further studies will be needed to validate these results in the clinical setting.

Published; Int J Prosthodont 2017;30:367-369. doi: 10.11607/ijp.5179

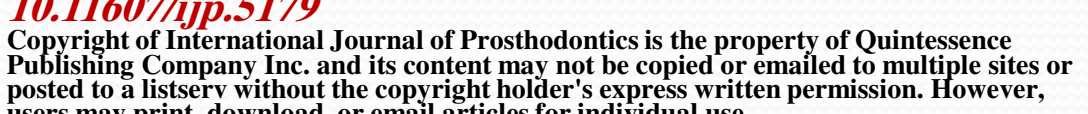
Acknowledgments: The authors thank Neo Biotech Co, LTD (Seoul, Korea) for their support in terms of dental implant fixtures, surgical drills, and the CAD/CAM surgical guide. The authors reported no conflicts of interest related to this study.

\section{References}

1. Tardieu PB, Vrielinck L, Escolano E, Henne M, Tardieu AL. Computer-assisted implant placement: Scan template, simplant, surgiguide, and SAFE system. Int J Periodontics Restorative Dent 2007;27:141-149.

2. Lee CY, Ganz SD, Wong N, Suzuki JB. Use of cone beam computed tomography and a laser intraoral scanner in virtual dental implant surgery: Part 1. Implant Dent 2012;21:265-271. 3. Lal K, White GS, Morea DN, Wright RF. Use of stereolithographic templates for surgical and prosthodontic implant planning and placement. Part I. The concept. J Prosthodont 2006;15:51-58. 4. Widmann G, Bale RJ. Accuracy in computeraided implant surgery-A review. Int J Oral Maxillofac Implants 2006;21:305-313. 